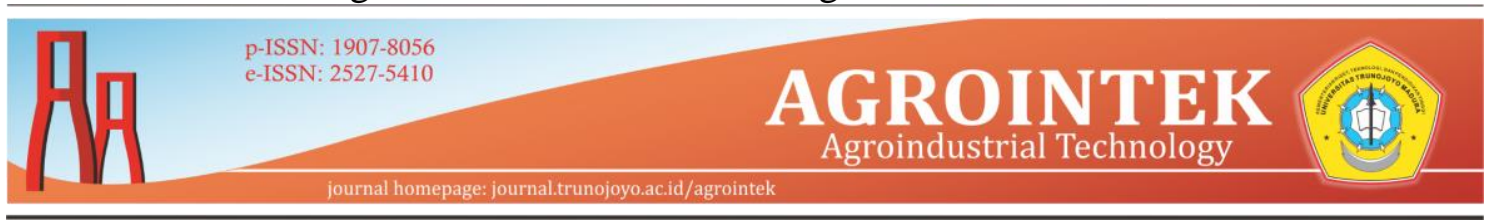

\title{
OPTIMASI PEMAKAIAN JAM KERJA DAN BAHAN BAKU DALAM MEMPRODUKSI MINUMAN INSTAN TRADISIONAL
}

\author{
Sondang Kiki Rosita ${ }^{1 \dagger}$, Totok Herwanto ${ }^{1}$, Ahmad Thoriq $^{1}$, Boy Macklin Pareira ${ }^{1}$ \\ ${ }^{1}$ Jurusan Teknik Pertanian dan Biosistem, Fakultas Teknologi Industri Pertanian, Universitas \\ Padjadjaran
}

Article history

Diterima: 12 Maret 2019

Diperbaiki:17 Juni 2019

Disetujui:26 Juni 2019

$\underline{\text { Keyword }}$

Minuman Instan,

Optimasi,

Goal Programming,

LINDO

\begin{abstract}
CV. Cihanjuang Inti Teknik is a small or medium-sized business (UKM) engaged in the traditional beverage processing industry. The company is faced with problems of use to optimize the use of work time so that there is no idle work time or overtime working hours. Other problems, so far the procurement of raw materials carried out is also only based on estimates, namely with raw materials made in stock without taking into account quantitative calculations. The goal programming method is used with the aim of analyzing and describing the optimal use of resources in working hours and raw materials from the average production target needed by the company. The calculation of goal programming is supported by using LINDO (Linear Interactive Discrete Optimizer) program to obtain the optimal number of products from working hours and raw materials needed by the company. The results of the study obtained optimal regular working hours in scenarios I, II, III, and IV respectively in the amount of 159.95 hours/month, 174.25 hours/month, 176.26 hours/month and 192.37 hours/month. There was also an increase in the use of raw materials for ginger, coffee, ginseng and pepper in scenario II, raw materials for ginger, white and vanilla sugar in scenario III, raw materials for white sugar, vanilla and cinnamon in scenario $I V$.
\end{abstract}

(C) hak cipta dilindungi undang-undang

\footnotetext{
$\dagger$ Penulis korespondensi

Email: sondangkiki@gmail.com

DOI: http://dx.doi.org/10.21107/agrointek.v13i2.5052
} 


\section{PENDAHULUAN}

Saat ini persaingan dunia usaha di era globalisasi ini sangatlah ketat. Melihat dari permasalahan tersebut perusahaan harus memiliki strategi yang matang serta dipacu untuk dapat berproduksi secara efektif dan efisien sehinggga mampu bersaing dengan perusahaan lain. Dalam hal ini tentunya suatu perusahaan juga mengharapkan agar tercapai keuntungan sesuai dengan target yang direncanakan.

Upaya dalam mencapai tujuan tersebut diperlukan kegiatan yang menunjang kelancaran proses produksi dalam suatu perusahaan. Salah

satu faktor untuk menghasilkan produk yang efektif dan efisien adalah dengan melakukan optimasi produksi dengan harapan untuk mendapatkan keuntungan yang maksimal dengan biaya seminimal mungkin. Optimasi produksi diperlukan perusahaan dalam rangka untuk mengoptimalkan sumber daya yang digunakan agar suatu produksi dapat menghasilkan produk dalam kuantitas dan kualitas yang diharapkan, sehingga perusahaan dapat mencapai tujuannya (Andini dan Slamet, 2016).

CV. Cihanjuang Inti Teknik merupakan salah satu UMKM yang menjual minuman tradisional instan dalam bentuk kemasan. Perusahaan ini terbilang cukup sukses di Cimahi yang menerima banyak penghargaan sehingga dijadikan UKM percontohan untuk UKM sekitar Cimahi. Minuman instan tradisional yang diproduksi adalah Bandrek original, Kopi Bandrek, Bandrek Coklat, Bandrek Special, Bandrek En Teh, Bajigur Original, Kopi Bajigur, Sekoteng, dan Beas Cikur. Sebagai usaha yang memproduksi minuman instan tradisional tidak terlepas dari permasalahan atau kendala selama selama proses produksi berlangsung. Kendala proses produksi diantaranya adalah kapasitas produksi, jam kerja, dan jumlah permintaan yang bersifat tidak stabil (Cahaya, 2014). Jumlah jam kerja yang terbatas dalam produksi dengan permintaan yang bersifat fluktuaktif dan tidak pasti menyebabkan adanya jam kerja yang tidak terpakai ataupun perusahaan harus mengandalkan jam kerja lembur selama proses produksi sehingga akan meningkatkan biaya produksi.Maka dari itu, perusahaan dihadapkan dalam permasalahan untuk mengoptimalkan pemakaian jam kerja agar tidak terjadi jam kerja mengangur atau pun kelebihan pemakaian jam kerja.

Permasalahan lainnya, selama ini ketersediaan bahan baku yang dilakukan juga hanya berdasarkan perkiraan saja yaitu dengan bahan baku untuk dijadikan stok tanpa adanya perhitungan sebagaimana bahan baku terpakai dalam proses produksinya. Hal ini beresiko karena dapat menimbulkan permasalahan adanya penimbunan bahan baku yang dapat mengakibatkan adanya biaya simpan.

Proses produksi merupakan hal yang sangat penting pada perusahaan manufaktur. Faktor produksi seperti kapasitas mesin, bahan baku, modal, dan lain-lain perlu diperhatikan dalam menunjang jalannya proses produksi. Persediaan bahan baku yang pada umumnya belum optimal pada suatu industri kecil kelompok pangan perlu optimasi yang didasarkan pada kecocokan model persediaan masing-masing bahan baku yang digunakan. Berikut dengan jam kerja dimana setiap perusahaan memiliki jam kerja yang terbatas. Pemakaian waktu yang efektif dan efisien dengan jumlah perkerja yang beroperasi akan mempengaruhi pendapatan yang dapat diterima perusahaan. Maka dari itu dibutuhkan suatu model perhitungan untuk menghitung pemakaian bahan baku dan jam kerja yang optimal sehingga diperoleh juga kombinasi jumlah produksi 
yang optimal yang perlu diproduksi perusahaan. Permasalahan optimasi ntuk tujuan-tujuan yang ingin dicapai tersebut dapat dihitung dengan menggunakan metode goal programming. Metode lain dalam permasalahan optimasi produksi dapat menggunakan linear programming. Namun metode ini dirasa kurang fleksibel karena fungsi kendala dan fungsi tujuan yang dapat digunakan hanya satu.

Metode goal programming adalah suatu model matematis yang digunakan untuk menganalisis dan membuat solusi persoalan yang melibatkan banyak tujuan sehingga diperoleh alternatif pemecahan masalah yang optimal (Susanti, 2013). Metode Goal Programming sangat efektif dalam optimasi karena metode ini potensial dalam penyelesaian aspek-aspek yang bertentangan antar elemen-elemen perencanaan seperti konsumen, produk dan proses manufaktur (Novitasari, 2013). Aplikasi model goal programming dalam optimasi juga pernah dilakukan pada penelitian sebelumnya dalam mengoptimalisasi batasan sumber daya dengan sasaran memaksimalkan jumlah produksi serta meminimumkan jam kerja untuk produk crum rubber (pengolahan karet mentah setengah jadi) (Devani, 2013).

\section{METODE}

Subjek penelitian ini adalah persediaan bahan baku pada CV. Cihanjuang Inti Teknik Kota Cimahi, Jawa Barat.. Alat dan bahan yang digunakan dalam proses penelitian yaitu, software Microsoft Excel 2013, software LINDO, Microsoft Visio 2013. Data yang diambil terkait dengan penelitian adalah data ketersediaan bahan baku, data pemakaian bahan baku, data harga pokok dan harga jual produk, data jam kerja perusahaan, data produksi tahun 2017. Metode penelitian yang digunakan pada penelitian ini adalah metode analisis deskriptif, yaitu metode yang digunakan untuk menganalisa data dengan cara mendeskripsikan atau menggambarkan data yang telah terkumpul sebagaimana adanya tanpa bermaksud membuat kesimpulan yang berlaku untuk umum (Sugiyono, 2014).

Penelitian ini menggunakan 4 (empat) skenario yaitu skenario 1 optimasi produksi dengan memanfaatkan sumberdaya yang ada di perusahaan dengan syarat pemenuhan beberapa sasaran yang telah ditetapkan dan tanpa adanya penetapan target keuntungan. Skenario 2 optimasi produksi dengan memanfaatkan sumberdaya yang ada di perusahaan dengan syarat pemenuhan beberapa sasaran yang telah ditetapkan dan adanya penetapan target keuntungan sebesar $10 \%$. Skenario 3 optimasi produksi dengan memanfaatkan sumberdaya yang ada di perusahaan dengan syarat pemenuhan beberapa sasaran yang telah ditetapkan dan adanya penetapan target keuntungan sebesar $20 \%$. Skenario 4 optimasi produksi dengan memanfaatkan sumberdaya yang ada di perusahaan dengan syarat pemenuhan beberapa sasaran yang telah ditetapkan dan adanya penetapan target keuntungan sebesar $10 \%$

Optimasi pada skenario 1 ditujukan untuk mengetahui kondisi aktual produksi perusahaan. sedangkan skenario II,III, dan IV ditujukan untuk mengetahui tingkat optimal yang dapat dicapai dengan menetapkan target keuntungan yang hendak dicapai perusahaan dari kondisi actual. Keempat skenario tersebut kemudian dianalisis untuk melihat solusi optimal yang memungkinkan dapat diterapkan oleh perusahaan.

\section{Tahapan Penelitian}

Dalam mencapai tujuan penelitian, tahapan pada penelitian dimulai dari pengumpulan data. Data yang dikumpukan pada tahap ini adalah data khusus perusahaan. Pengumpulan data 
yang dilakukan juga adalah pengukuran waktu proses dalam sekali proses produksi minuman instan tradisional yang diambil langsung dari pengamatan di lini produksi dengan menggunakan stopwatch.

Kebutuhan data yang telah diperoleh, kemudian dibentuk menjadi model optimasi goal programming dengan tujuan yang ingin dicapai yaitu untuk memaksimasi jam kerja reguler, meminimasi jam kerja lembur, dan memaksimasi pemakaian bahan baku. Pengolahan data untuk menyelesaikan model tersebut dilakukan dengan menggunakan software LINDO 6.1 Setelah itu dilakukan analisis hasil data dalam menyelesaikan masalah tersebut.

\section{Formulasi \\ Matematis \\ Goal programming}

Tahapan dalam formulasi Goal programming adalah sebagai berikut: (Novitasari, 2017)

1) Perumusan variabel keputusan

Variabel keputusan merupakan output yang akan dioptimalkan untuk memenuhi kriteria kendala dan tujuan. Dalam penelitian ini, variabel keputusan yang dipilih adalah jumlah produksi dari setiap varian produk minuman (Xi) dimana:

$$
\begin{array}{ll}
\mathrm{X}_{\mathrm{i}} & \text { : Jumlah produk ke-i } \\
\mathrm{i} & \text { : jenis produksi yang } \\
& \text { dihasilkan }(\mathrm{i}=1,2, . ., \mathrm{n})
\end{array}
$$

2) Perumusan fungsi kendala dan fungsi tujuan

a. Fungsi sasaran memenuhi volume produksi

Persamaan pengoptimalan jumlah produksi adalah sebagai berikut:

$X_{i}+d_{i}^{-}-d_{i}^{+}=P_{i}$

Dengan:

$\mathrm{X}_{\mathrm{i}} \quad$ : Jumlah produk ke-i

$\mathrm{P}_{\mathrm{i}} \quad$ : jumlah rata-rata produk ke-i

$\begin{array}{ll}\mathrm{i} & : \text { jenis produk }(1,2, \ldots, \mathrm{n}) \\ \mathrm{d}_{\mathrm{i}}^{-} & : \text {penyimpangan negatif } \\ & \text { (kekurangan) dari target } \\ & \text { produksi yang ditentukan } \\ \mathrm{d}_{\mathrm{i}}^{+} & : \text {penyimpangan positif } \\ & \text { (kelebihan) dari target } \\ & \text { produksi yang ditentukan }\end{array}$

b. Fungsi sasaran jam kerja reguler

Persamaan maksimasi jam kerja reguler adalah sebagai berikut:

$$
\sum_{\mathrm{i}=1}^{\mathrm{m}} \mathrm{A}_{\mathrm{ij}} \mathrm{x}_{\mathrm{i}}+\mathrm{d}_{j}^{-}-\mathrm{d}_{\mathrm{j}}^{+}=\mathrm{JKR}
$$

Dengan

$\mathrm{A}_{\mathrm{ij}}=$ waktu proses per pak produk ke- $i$

$\mathrm{x}_{\mathrm{i}} \quad=$ variabel keputusan untuk jenis produk ke-i

JKR $=$ ketersediaan jumlah jam kerja reguler

c. Fungsi ssaran jam kerja lembur

$\mathrm{d}_{\mathrm{ij}}^{+}+\mathrm{d}_{\mathrm{k}}^{-}-\mathrm{d}_{\mathrm{k}}^{+}=\mathrm{JKL}$

Dengan:

$d_{j}^{+} \quad$ : jumlah jam lembur

JKL : target jam kerja lembur

$d_{k}^{-} \quad:$ penyimpangan negatif (kekurangan) dari target jam kerja lembur

$d_{k}^{+} \quad:$ penyimpangan positif (kelebihan) dari target jam kerja lembur

d. Fungsi sasaran pemakaian bahan baku

$$
\sum_{j=1}^{18} \sum_{i=1}^{11} b_{m i} x_{i}+d_{l m}^{-}-d_{l m}^{+}=B_{j}
$$

Dengan:

$\mathrm{b}_{\mathrm{ij}} \quad$ : Jumlah pemakaian bahan baku a untuk produk i

$\mathrm{x} \quad$ : variabel keputusan untuk jenis produk ke-i

i $\quad$ : jenis produk $(i=1,2, \ldots, n)$

$\mathrm{Bj} \quad$ : Jumlah ketersediaan bahan baku a 
1 : jenis bahan baku $\quad(1=$ $1,2, \ldots, \mathrm{n})$

$d_{l m}^{-} \quad:$ penyimpangan negatif (kekurangan) dari target ketersediaan bahan baku $(\mathrm{m}=15,16, . . \mathrm{n})$

$d_{l m}^{+} \quad:$ penyimpangan negatif (kelebihan) dari target ketersediaan bahan baku $(\mathrm{m}=15,16, \ldots, \mathrm{n})$

3) Menformulasikan fungsi pencapaian dengan menggabungkan variabelvariabel keputusan dari fungsi kendala dan tujuan.

\section{HASIL DAN PEMBAHASAN}

\section{Analisis Pencapaian Sasaran Volume Produksi}

Output dari LINDO menghasilkan kombinasi jumlah produksi untuk memenuhi fungsi tujuan dan fungsi kendala yang dimiliki perusahaan. Pada tabel 1 dapat dilihat hasil optimasi jumlah produksi yang perlu dicapai perusahaan pada setiap skenario.

Kondisi aktual rata-rata produksi setiap bulan yang dihasilkan CV. Cihanjuang Inti Teknik yaitu sebesar 7.848 pack/bulan. Hasil optimasi skenario I menunjukkan bahwa tingkat produksi minuman instan tradisional mengalami peningkatan hingga mencapai 8.527 pack/bulan. Peningkatan produksi tersebut memiliki selisih sebesar 679 pack dari jumlah produksi sebelumnya. Jumlah produksi pada skenario II juga mengalami peningkatan hingga mencapai 9.097 pack/bulan dengan selisih 1.249 pack/bulan. Kemudian pada skenario III dan IV terdapat peningkatan produksi mencapai 9.309 pack/bulan dan 10.222 pack/bulan dengan selisih kedua skenario tersebut sebesar 1.461 pack/bulan dan $2.374 \mathrm{pack} / \mathrm{bulan}$ dari jumlah produksi aktual.

Berdasarkan hasil optimasi pada setiap skenario, terdapat beberapa yang tidak mengalami perubahan jumlah produksi dari kondisi sebelumnya dan terdapat juga produk dapat ditingkatkan jumlah produksinya. Jenis produk yang tidak mengalami peningkatan dari kondisi sebelumnya menandakan bahwa jenis produk tersebut sudah sesuai dengan kondisi optimalnya. Sedangkan, peningkatan produksi dari sasaran yang diinginkan disebabkan oleh adanya sumber daya yang tersedia dimana perusahaan masih memungkinkan untuk meningkatkan produksinya sampai batas maksimal pemanfaatan sumberdaya hasil tersebut, adanya peningkatan produksi tentunya akan berbanding lurus dengan peningkatkan keuntungan yang dapat diperoleh perusahaan.

\section{Analisis Pencapaian Sasaran Pemakaian Jam Kerja}

Pada tabel 2 dapat dilihat perhitungan jam kerja yang diperlukan perusahaan pada setiap kondisi.

Tabel 1. Hasil Pemakaian Jam Kerja Reguler Optimal dengan Menggunakan Goal Programming

\begin{tabular}{cccccc}
\hline & \multicolumn{5}{c}{ Pemakaian Jam Kerja (jam/bulan) } \\
\cline { 2 - 6 } $\begin{array}{c}\text { Ketersediaan } \\
\text { Jam Kerja } \\
\begin{array}{c}\text { Reguler } \\
\text { jam/bulan) }\end{array}\end{array}$ & Aktual & Sk. I & Sk. II & Sk. III & Sk. IV \\
\hline 160 & 149,22 & 160,68 & 174,25 & 176,26 & 192,37 \\
& & & & & \\
Selisih & $-11,22$ & $+0,68$ & $+14,25$ & $+16,26$ & $+32,37$
\end{tabular}

Kondisi aktual perusahaan dengan rata-rata produksi sebesar 7848 pack/bulan masih memiliki kelebihan jam kerja sebesar 11,22 jam/bulan. Kelebihan jam kerja juga terjadi pada skenario I, II, III, dan IV dengan adanya peningkatan sebesar 0,68 jam/bulan, 14,25 jam/bulan, $16,26 \mathrm{jam} / \mathrm{bulan}$, dan $32,37 \mathrm{jam} / \mathrm{bulan}$. Peningkatan jam kerja tersebut perlu diperhatikan oleh suatu perusahaan dalam produksi karena perusahaan perlu memberlakukan jam kerja lembur untuk memenuhi target produksi. Untuk 
meminimalisir adanya peningkatan jam kerja diluar target perusahaan, perusahaan perlu meningkatkan kecepatan produksinya dengan peningkatan tenaga kerja terutama pada bagian pengemasan.

Dalam hal ini, sangat penting bagi perusahaan untuk menentukan kapasitas produksi dalam rangka mengukur tingkat kemampuan dalam memproduksi sejumlah unit. Kapasitas produksi dapat dijadikan dasar bagi perusahaan untuk mengambil kebijakan dalam kesanggupan menerima pesanan. (Supriyanto, 2014)

\section{Analisis Pencapaian Sasaran Jam Kerja Lembur}

Pada tabel 3 dapat dilihat pemakaian jam kerja lembur pada skenario I, II, III, dan IV.

Tabel 2. Hasil Pemakaian Jam Kerja Lembur Optimal dengan Menggunakan Goal Programming

\begin{tabular}{ccccc}
\hline $\begin{array}{c}\text { Ketersediaan Jam } \\
\text { Kerja Reguler } \\
\text { (jam/bulan) }\end{array}$ & \multicolumn{4}{c}{$\begin{array}{c}\text { Pemakaian Jam Kerja Lembur } \\
\text { (jam/bulan) }\end{array}$} \\
\cline { 2 - 5 } & Sk. I & Sk. II & Sk. III & Sk. IV \\
\hline 32 & 0,68 & 14,25 & 16,26 & 32,37 \\
Selisih & 0 & 0 & 0 & 0,37
\end{tabular}

Berdasarkan hasil optimasi goal programming, kelebihan jam kerja yang terjadi pada skenario I, II, dan III adalah sebesar $0,68 \mathrm{jam} / \mathrm{bulan}, 14,25 \mathrm{jam} / \mathrm{bulan}$, dan 16,26 jam/bulan dimana nilai tersebut masih berada pada batas yang diperbolehkan perusahaan yaitu dibawah 32 jam/bulan. Sedangkan pada skenario IV, kelebihan jam kerja lembur sebesar 32,37 jam/bulan dimana selisih jam kerja yang dipakai dari jumlah yang tersedia adalah sebesar 0,37 jam/bulan atau setara dengan 22,2 menit/ bulan. Hasil optimasi tersebut menunjukkan semakin tinggi permintaan tentunya akan menuntut peningkatan kapasitas perusahaan.
Namun, peningkatan kapasitas produksi tidak selamanya dapat meningkatakan keuntungan lebih tinggi dikarenakan setiap perusahaan memiliki kapasitas produksi maksimum. (Nursanti, 2015.) Maka dari itu, peningkatan jam kerja lembur perlu diperhatikan oleh perusahaan karena hal ini berpotensi menimbulkan peningkatan biaya untuk upah tenaga kerja.

\section{Analisis Pencapaian Pemakaian Bahan Baku}

Pada penelitian ini, tujuan yang ingin dicapai yaitu mengoptimalkan pemakaian bahan baku. Dari tabel 4 dapat dilihat bahwa pemakaian bahan baku pada kondisi actual dab skenario I lebih kecil dari ketersediaannya sehingga dalam hal ini perusahaan masih dapat mengoptimalkan bahan baku yang tersedia untuk meningkatkan produksinya.

Hasil optimasi skenario II, III, dan IV terjadi peningkatan pemakaian bahan baku karena adanya peningkatan poduksi. Adanya peningkatan bahan baku tersebut dapat menjadi informasi untuk perusahaan dalam mengantisipasi peningkatan jumlah ketersediaan bahan setiap bulannya apabila perusahaan berproduksi sesuai dengan hasil optimasi pada skenario I,II, III, dan IV. Perusahaan juga perlu memperhatikan kebutuhan bahan baku karena bahan baku memiliki peran penting dalam menjamin kelancaran kegiatan produksi yang disesuaikan dengan kapasitas gudang yang dimiliki perusahaan. Peningkatan ketersediaan bahan baku juga akan meningkatkan biaya produksi. Untuk itu faktor ini harus dipertimbangkan oleh perusahaan karena peningkatan ketersediaan bahan baku akan mempengaruhi besar keuntungan yang dapat diperoleh perusahaan. 
Tabel 3. Hasil Jumlah Optimal dengan Menggunakan Goal Programming

\begin{tabular}{|c|c|c|c|c|c|}
\hline \multirow{2}{*}{ Produk } & \multirow{2}{*}{ Aktual } & \multicolumn{4}{|c|}{ Hasil Optimasi pack/ Bulan } \\
\hline & & Sk. I & Sk. II & Sk. III & Sk.IV \\
\hline $\begin{array}{l}\text { Bandrek } \\
\text { Klasik }\end{array}$ & 2280 & 2280 & 2878 & 3057 & 2280 \\
\hline Bandrek Kopi & 218 & 218 & 218 & 218 & 325 \\
\hline $\begin{array}{l}\text { Bandrek En } \\
\text { Teh }\end{array}$ & 198 & 233 & 198 & 198 & 233 \\
\hline $\begin{array}{l}\text { Bandrek } \\
\text { Spesial }\end{array}$ & 1041 & 1041 & 1434 & 1041 & 1041 \\
\hline $\begin{array}{l}\text { Bandrek } \\
\text { Coklat }\end{array}$ & 297 & 297 & 297 & 297 & 333 \\
\hline Bajigur Klasik & 1490 & 1773 & 1490 & 1490 & 3174 \\
\hline Bajigur Kopi & 248 & 248 & 506 & 382 & 248 \\
\hline Sekoteng & 496 & 496 & 496 & 496 & 806 \\
\hline Beas Cikur & 298 & 298 & 298 & 476 & 476 \\
\hline $\begin{array}{l}\text { Bandrek } \\
\text { Renteng }\end{array}$ & 689 & 1050 & 689 & 689 & 713 \\
\hline $\begin{array}{l}\text { Bajigur } \\
\text { Renteng }\end{array}$ & 593 & 593 & 593 & 965 & 593 \\
\hline Jumlah & 7.848 & 8.527 & 9.097 & 9.309 & 10.222 \\
\hline
\end{tabular}

\section{Analisis Sensitivitas}

Analisis sensitivitas menunjukkan bagaimana kepekaan model pada kondisi optimal apabila terjadi perubahan pada model. Melalui analisis sensitivitas dapat dilihat sejauh mana perubahan batas kenaikan dan penurunan yang diperbolehkan untuk mempertahankan solusi optimal.

Pada tabel 5 dapat diketahui kendala jam kerja reguler pada row 14 menunjukkan bahwa peningkatan jam kerja yang diperbolehkan sebesar 1,32 $\mathrm{jam} /$ bulan dengan batas penurunan yang diperbolehkan sebesar $0,11 \mathrm{jam} / \mathrm{bulan}$ pada skenario I. Skenario II menunjukkan peningkatan jam kerja yang diperbolehkan yaitu sebesar 14,26 dan 17,73 jam/bulan untuk batas penurunan yang diperbolehkan. Pada skenario III juga terdapat batas peningkatan yang diperbolehkan yaitu sebesar 16,29 jam/bulan dengan batas penurunan sebesar 15,70 jam/bulan. Sedangkan skenario IV, batas peningkatannya yang diperbolehkan sebesar 0,44 jam/bulan dan batas penurunan yang diperbolehkan sebesar tak terhingga.

Pada jam kerja lembur batas kenaikan dari skenario I hingga skenario III adalah tak terhingga dengan batas penurunan yang diperbolehkan sebesar $32 \mathrm{jam} / \mathrm{bulan}$ pada skenario I, 17,73 jam/bulan pada 
skenario II dan 22.95 jam/bulan pada skenario III. Berbeda dengan skenario IV jam/bulan dengan batas penurunan sebesar dimana batas kenaikan yang diperbolehkan yaitu sebesar 0.44 tak terhingga.

Tabel 4. Hasil Pemakaian Bahan Baku Optimal dengan Menggunakan Goal Programming

\begin{tabular}{|c|c|c|c|c|c|c|c|}
\hline \multirow[b]{2}{*}{ No } & \multirow[b]{2}{*}{ Bahan Baku } & \multirow{2}{*}{$\begin{array}{l}\text { Ketersediaan } \\
\text { Bahan Baku } \\
(\mathrm{kg}) / \mathrm{bulan}\end{array}$} & \multicolumn{5}{|c|}{ Total Pemakaian Bahan Baku (kg)/bulan } \\
\hline & & & Aktual & Sk. I & Sk. II & Sk.III & Sk. IV \\
\hline 1 & Jahe & 900 & 797,94 & 889,88 & 930,57 & 915,64 & 890,88 \\
\hline 2 & Gula Merah & 5000 & 3993,92 & 4489,48 & 4540,33 & 4942,39 & 4998,45 \\
\hline 3 & Serai & 250 & 183,70 & 204,52 & 215,69 & 212,60 & 199,51 \\
\hline 4 & Cabe Jawa & 210 & 176,80 & 199,82 & 203,92 & 209,98 & 195,851 \\
\hline 7 & Garam & 240 & 116,18 & 131,247 & 131,67 & 141,13 & 144,08 \\
\hline 8 & Creamer & 2500 & 1993,42 & 2219,94 & 2277,67 & 2386,19 & 2461,73 \\
\hline 9 & Vanila & 110 & 98,75 & 109,94 & 108,35 & 131,86 & 146,39 \\
\hline 10 & Beras & 40 & 25,03 & 39,98 & 25,032 & 39,98 & 39,98 \\
\hline 11 & Kencur & 40 & 25,03 & 39,98 & 25,032 & 39,98 & 39,98 \\
\hline 15 & Kayu Manis & 15 & 14,88 & 14,88 & 14,88 & 14,88 & 18,42 \\
\hline 16 & Kacang & 55 & 7,936 & 7,94 & 7,936 & 7,936 & 9,824 \\
\hline 17 & Buah Kering & 60 & 7,936 & 7,94 & 7,936 & 7,936 & 9,824 \\
\hline 18 & Ginseng & 15 & 12,90 & 12,91 & 17,78 & 12,90 & 12,90 \\
\hline 19 & Merica & 32 & 25,81 & 25,81 & 35,56 & 25,81 & 25,81 \\
\hline
\end{tabular}

Hasil dari template yang diperlihatkan dalam bentuk lembar kerja ARD (Gambar 5), selanjutnya dihubungkan dengan simbol-simbol berupa garis-garis yang memperlihatkan gambaran bagaimana keterkaitan dan keeratan hubungan antar fasilitas proses produksi seperti ditunjukkan oleh Gambar 6.

\section{Analisis Tata Letak Perbaikan Fasilitas Proses Produksi dengan Blocplan-90}

Gambar 7 berikut memperlihatkan bentuk aplikasi perancangan tata letak menggunakan aplikasi software Blocplan90, yang menggambarkan bagaimana bentuk hubungan antar aktifitas atau ARC, bersamaan dengan itu ditentukan pula luas setiap ruang yang digunakan dalam proses produksi. Selanjutnya mengacu pada layout awal perusahaan sebagai input data pada ARC menggunakan Blocplan dapat diketahui hasilnya seperti dalam Tabel 2
Tabel 2 menunjukkan bahwa layout score awal menggunakan Blocplan menghasilkan 0.78 dengan jarak kedekatan 107 - 1. Pada pengolahan data kualitatif ARC perbaikan melalui menu pilihan Blocplan dipilih single story layout menu. Single story layout merupakan menu dimana data kualitatif dimasukkan, tersimpan dan dapat diganti jika ada perbaikan. Langkah selanjutnya, dalam mencari layout optimal dan proses output yang cepat pada letak terbaik dengan menggunakan menu automatic search. Secara acak menu tersebut akan menunjukkan 20 layout dengan berbagai score layout. Hasil pencarian automatic search dalam menu single story layout ditunjukkan oleh Tabel 3.

Tabel 3 menunjukkan alternatif penyelesaian tata letak dengan kriteria untuk pemilihan alternatif tata letak adalah adjacency score (nilai hubungan kedekatan), R-score (efisiensi layout) dan 
Relative distance (jarak). Menurut Jaya et al., (2017) nilai R-Score (normalized relationship distance score) yang mendekati nilai 1 menunjukan bahwa layout tersebut optimal. Nilai adjacency score (nilai hubungan kedekatan) dengan mendekati nilai 1.00-1 terdapat pada layout nomor $1,2,3,4,6,7,8,10,12,13$,
14, 15, 16, 18 dan 20. Pada layout nomor 14 dengan nilai $\mathrm{R}$-score 0.98 karena mendekati nilai 1 dengan jarak kedekatan 38 - 3. Hal ini menjadikan R-score 0.98 merupakan layout terbaik dari 20 layout secara automatic search pada blocplan. Hasil layout dapat dilihat Gambar 7.

Tabel 5. Analisis sensisitivitas Righthand Side (RHS)

\begin{tabular}{|c|c|c|c|c|c|c|c|c|c|}
\hline \multirow{2}{*}{ Row } & \multirow{2}{*}{$\begin{array}{c}\text { Current } \\
\text { RHS }\end{array}$} & \multicolumn{2}{|c|}{ Sk. I } & \multicolumn{2}{|c|}{ Sk. II } & \multicolumn{2}{|c|}{ Sk. III } & \multicolumn{2}{|c|}{ Sk. IV } \\
\hline & & AI & $\mathrm{AD}$ & $\mathrm{AI}$ & $\mathrm{AD}$ & AI & $\mathrm{AD}$ & AI & $\mathrm{AD}$ \\
\hline 14 & 160 & 1.32 & 0.11 & 14.26 & 17.73 & 16.29 & 15.70 & 0.44 & Infinity \\
\hline 15 & 32 & Infinity & 16.00 & Infinity & 17.73 & Infinity & 15.70 & 0.44 & Infinity \\
\hline 16 & 900.00 & 2.21 & 24.84 & 37.87 & Infinity & 22.95 & Infinity & 50.89 & 31.42 \\
\hline 17 & 5000.00 & Infinity & 508.99 & Infinity & 459.41 & Infinity & 56.24 & 20.13 & 40.94 \\
\hline 18 & 250.00 & Infinity & 45.40 & Infinity & 34.29 & Infinity & 37.38 & Infinity & 50.39 \\
\hline 19 & 210.00 & Infinity & 10.14 & Infinity & 6.06 & 15.24 & 2.55 & Infinity & 14.06 \\
\hline 20 & 148.00 & Infinity & 3.15 & 2.59 & 0.92 & 1.70 & Infinity & Infinity & 6.51 \\
\hline 21 & 3500.00 & Infinity & 88.54 & 53.67 & 15.87 & 196.37 & Infinity & 272.97 & Infinity \\
\hline 22 & 240.00 & Infinity & 108.70 & Infinity & 108.31 & Infinity & 98.83 & Infinity & 95.85 \\
\hline 23 & 2500.00 & Infinity & 293.46 & Infinity & 234.05 & Infinity & 125.10 & Infinity & 50.68 \\
\hline 24 & 110.00 & 0.63 & 7.15 & Infinity & 1.64 & 21.94 & Infinity & 36.41 & Infinity \\
\hline 25 & 40.00 & Infinity & 0.00 & Infinity & 14.96 & 0.00 & 14.96 & 20.11 & 0.00 \\
\hline 26 & 40.00 & 0.00 & 8.18 & Infinity & 14.96 & Infinity & 0.00 & 0.00 & Infinity \\
\hline 27 & 65.00 & Infinity & 12.27 & 12.23 & Infinity & 40.11 & 13.36 & 41.26 & 13.36 \\
\hline 28 & 35.00 & 1.20 & 5.3 & Infinity & 5.30 & Infinity & 5.30 & 6.54 & 5.30 \\
\hline 29 & 50.00 & 1.20 & 5.45 & Infinity & 5.45 & Infinity & 5.45 & 6.27 & 5.45 \\
\hline 30 & 15.00 & Infinity & 0.12 & Infinity & 0.12 & Infinity & 0.12 & 3.44 & Infinity \\
\hline 31 & 55.00 & Infinity & 47.06 & Infinity & 47.06 & Infinity & 47.06 & Infinity & 45.16 \\
\hline 32 & 60.00 & Infinity & 52.06 & Infinity & 52.06 & Infinity & 52.06 & Infinity & 50.16 \\
\hline 33 & 15.00 & Infinity & 2.09 & 2.78 & Infinity & Infinity & 2.09 & Infinity & 2.09 \\
\hline 34 & 32.00 & Infinity & 6.18 & 3.56 & Infinity & Infinity & 6.18 & Infinity & 6.18 \\
\hline
\end{tabular}

Keterangan:

AI : Batas peningkatan yang diperbolehkan (Allowance Increase)

$\mathrm{AD}$ : Batas penurunan yang diperbolehkan (Allowance Decrease) 
Selain itu diketahui juga kendala ketersediaan bahan baku yang dapat dilihat pada row 16 sampai row 34. Pada contoh ketersediaan bahan baku jahe pada row 16 skenario I dimana peningkatkan ketersediaan bahan baku yang diizinkan adalah tak terhingga dan jahe hanya boleh dikurangi sebanyak $24.84 \mathrm{~kg} / \mathrm{bulan}$. Skenario II menunjukkan hasil yang berbeda dimana batas peningkatan jahe hanya boleh pada $37,87 \mathrm{~kg} /$ bulan dengan batas penurunan maksimal sebesar tak terhingga. Selanjutnya, skenario III memberikan batas penurunan sebesar tak terhingga dengan batas kenaikan maksimal 22,95 kg/bulan. Kemudian pada skenario IV kenaikan bahan baku jahe yang diperbolehkan sebesar $0,44 \mathrm{~kg} / \mathrm{bulan}$ dengan batas penurunan sebear 31,42 $\mathrm{kg} / \mathrm{bulan}$.

Kenaikan tidak terhingga yang disajikan pada tabel 5 disebabkan oleh adanya sumberdaya yang tidak habis terpakai sehingga adanya penambahan sumberdaya tidak akan mengubah produksi optimalnya. Kondisi tersebut disebabkan karena sumberdaya yang tersedia mempunyai kelebihan dari penggunaan yang seharusnya (Pangabean, 2016). Maka dari itu apabila adanya penambahan jumlah bahan baku maka akan merugikan perusahaan karena dapat menimbulkan adanya penambahan biaya simpan.

Hasil analisis ini dapat diketahui batas yang diperbolehkan agar tetap mendapatkan keuntungan optimal. Dengan melihat nilai-nilai batas minimum dan batas maksimum tiap fungsi kendala sumberdaya, maka perusahaan dapat memperoleh informasi dalam melakukan penyesuaian terhadap pengadaan sumberdaya untuk mengurangi biayabiaya produksi yang diakibatkan oleh persediaan sumberdaya (Pangabean, 2016).

\section{KESIMPULAN}

1) Adapun kesimpulan yang dapat ditarik dari penelitian mengenai optimasi pemakaian jam kerja dan bahan baku dalam memproduksi minuman instan tradisional yang di lakukan di CV. Cihanjuang Inti Teknik, yaitu:

2) Jam kerja optimal yang digunakan pada skenario I,II, III, dan IV adalah sebesar 159,95 jam/bulan, 174,25 jam/bulan, 176,26 jam/bulan dan 192,37 jam/bulan dimana terdapat peningkatan sebesar 14,25 jam, 16,26 jam, dan 32,37 jam setiap bulannya pada skenario II,III, dan IV.

3) Bahan baku yang tersedia dapat dimaksimalkan namun terdapat peningkatan kebutuhan bahan baku jahe, kopi, gingseng dan merica pada skenario II, bahan baku jahe, gual putih dan vanilla pada skenario III, bahan baku gula putih, vanilla, dan kayu manis pada skenario IV.

\section{DAFTAR PUSTAKA}

Andini dan Slamet. 2016. Analisis Optimasi Persediaan Bahan Baku dengan Menggunakan Metode Economic Order Quantity pada CV. Tenun/ Atbm Rimatex Kabupaten Pemalang. Management Analysis Journal, 5 (2), 143-148.

D. Cahaya N., I. Santoso, and M. Effendi, "Perencanaan Produksi Keripik Kentang Menggunakan Metode Fuzzy Linear Programming (FLP) (Studi Kasus di UKM Agronas Gizi Food Kota Batu)," no. December 2014, pp. 1-7, 2014.

Devani. 2013. Optimasi Perencanaan Produksi dengan menggunakan Metode Goal Programming. Jurnal Sains, 11(1), 84-91.

Novitasari, N. 2013. Penggunaan Metode Goal Programming Untuk Optimasi 
Perancangan Proses Produksi Produk Wingko Babat. Applied Industrial

Engineering Journal, 1(2), 47-52.

Novitasari. 2013. Pendekatan metode goal programming dalam optimasi perencanaa produksi. Jurnal Mahasiswa Matematika, 1(3), 176179.

Nursanti E, Purnam, R.Suardika,I. 2015. Optimasi kapasitas produksi untuk mendapatkan keuntungan maksimum dengan Linear Programming. Jurnal Performa 14(1), 61-68

Pangabean, D. 2014. Optimasi perencanaan keuntungan produksi pada pengolahan rending di perusahaan "rendang erika" payakumbuh. Jurnal Optimasi Sistem Industri, 13(1), 427-253.

Sugiyono. 2014. Metode Penelitian Kuantitatif, Kualitatif, dan Kombinasi (Mix Methods). Bandung: Alfabeta.

Supriyanto. 2014. Otimasi Waktu/Proses Produksi di PT. Sumiden Sintered Component Indonesia dengan Teknik Analisa Network/Pert dan Metode Smed. Jurnal PASTI 8(3), $362-398$.

Susanti R. 2013. Optimasi Perencanaan Produksi untuk produk Pesanan Pada Perusahaan Pestisida Menggunakan Metode Goal Programming. Jurnal Teknik Industri. 2(1), 1-10. 